\title{
High saturated fat and low starch and fibre are associated with hyperinsulinaemia in a non-diabetic population: The San Luis Valley Diabetes Study
}

\author{
J .A . M arshall ${ }^{1}$, D.H . B essesen ${ }^{2}$, R .F. H amman ${ }^{1}$ \\ ${ }^{1}$ Department of Preventive Medicine and Biometrics, University of Colorado School of Medicine, Denver, Colorado, USA \\ ${ }^{2}$ Department of Medicine, University of Colorado School of Medicine, Denver, Colorado, USA
}

Summary A geographically based sample of 1069 Hispanic and non-Hispanic white persons aged 20 74 years, living in southern Colorado and who tested normal on an oral glucose tolerance test (World Health Organization criteria) were evaluated to determine associations of dietary factors with fasting serum insulin concentrations. Subjects were seen for up to three visits from 1984 to 1992 . A 24-h diet recall and fasting insulin concentrations were collected at all visits. In longitudinal data analysis, lower age, female gender, Hispanic ethnicity, higher body mass index, higher waist circumference, and no vigorous activity were significantly related to higher fasting insulin concentrations. High total and saturated fat intake were associated with higher fasting insulin concentrations after adjusting for age, sex, ethnicity, body mass index, waist circumference, total energy intake and physical activity. Dietary fibre and starch intake were inversely associated with fasting insulin concentrations. No associations with fasting insulin concentrations were observed for monounsaturated fat, polyunsaturated fat, sucrose, glucose and fructose intake. Associations were similar in men and women and for active and inactive subjects, though associations of fibre and starch intake with insulin concentrations were strongest in lean subjects. These findings support animal studies and a limited number of human population studies which have suggested that increased saturated and total fat intake and decreased fibre and starch intake increase fasting insulin concentrations and may also increase insulin resistance. These findings, which relate habitual macronutrient consumption to hyperinsulinaemia in a large population, may have implications for studies attempting primary prevention of non-insulin-dependent diabetes mellitus. [Diabetologia (1997) 40: 430438]

Keywords Fasting insulin, insulin resistance, dietary fats, dietary fibre, Hispanics.
Received: 6 August 1996 and in revised form: 17 December 1996

Corresponding author: Dr. J. A. Marshall, Department of Preventive Medicine and Biometrics, University of Colorado Health Sciences Center, Campus Box C-245, Denver, CO 80262, USA

A bbreviations: NIDDM, Non-insulin-dependent diabetes mellitus; SLVDS, San Luis Valley Diabetes Study; IGT, impaired glucose tolerance; BMI, body mass index; SAS, Statistical Analysis System; ADA, American Diabetes Association; GIP, gastric inhibitory polypeptide; NEFA, non-esterified fatty acids.
Hyperinsulinaemia, a marker for insulin resistance, has been associated with significant adverse outcomes. Hyperinsulinaemia is frequently associated with hypertension, hyperlipidaemia and coronary heart disease [1], and independent of obesity, predicts subsequent development of non-insulin-dependent diabetes mellitus (NIDDM) [1-4]. Identification of modifiable risk factors for the development of insulin resistance offers the potential for primary prevention of these important public health problems. Modification of the macronutrient composition of the diet is an intervention that has been advocated by some to improve insulin sensitivity. Specifically, diets reduced in total fat, saturated fat, and sucrose as well as relative increases in intakes of polyunsaturated fat, 
monounsaturated fat, and fibre have been suggested [5]. Data in support of these recommendations have come from short-term intervention studies where effects of increasing or reducing the amount of these nutrients in the diet on insulin sensitivity were measured in humans [6] and animals [7]. In addition, the effects of changes in these nutrients have been extensively studied in those with NIDDM [8] and it may be tempting to extrapolate the results of these studies to those with insulin resistance without frank diabetes. However, extrapolations from short-term studies, and studies done on subjects with NIDDM leave doubt about the relation of long-term effects of dietary factors on insulin levels in non-diabetic subjects.

Another approach to this important area of controversy is to examine the relationship between insulin sensitivity and the habitual intake of diets of differing macronutrient composition in free-living populations. A limited number of observational studies examining these relationships in humans have been conducted. Previous studies have looked primarily at fat intake and consistent positive associations between total and saturated fat intake and hyperinsulinaemia have been reported [9-12]. Less information is available for fibre, starch, sucrose or individual fatty acids. Previously, we reported that high fat/low carbohydrate intakes were associated with worsening glucose tolerance both cross-sectionally [13] and prospectively [14]. The study reported here investigates the association of the major macronutrients, subtypes of fat and carbohydrate and dietary fibre with hyperinsulinaemia in a non-diabetic, bi-ethnic population reporting their usual dietary intake.

\section{Subjects and methods}

Study population. The San Luis Valley Diabetes Study (SLVDS) was designed to study aetiologic and prognostic risk factors associated with NIDDM. In addition to seeing all known diabetic subjects in the study area, a geographically based sample of 1351 persons 20-74 years of age and without a prior history of diabetes were seen for a baseline visit during the period May 1984 to August 1988. An oral glucose tolerance test and the 1985 World Health Organization (WHO) criteria for diabetes [15] were used to classify subjects with normal glucose tolerance $(n=1107)$, impaired glucose tolerance (IGT) $(n=173)$, and previously undiagnosed diabetes $(n=71)$. Detailed methods are reported elsewhere [16]. Only subjects with normal glucose tolerance at baseline are included here. Of the 1107 subjects with normal glucose tolerance, 21 subjects subsequently classified as NIDDM at follow-up were excluded. Of the remaining 1086 subjects, 805 were seen for a follow-up visit an average of 4.3 years (range 3.0 to 7.6 years) after their baseline visit. Of these 805 subjects, 26 were classified as having IGT at their first follow-up visit and were rescreened after an average 1.6 years (range 0.9 to 2.3 years) and determined to be non-diabetic. After excluding 35 visits due to missing data, the final sample included 281 subjects with one visit, 757 subjects with two visits and 26 subjects with three visits.
Table 1. Subject characteristics and mean fasting insulin concentrations at baseline $(n=1069)$, San Luis Valley, Colorado, 1984-1988

\begin{tabular}{|c|c|c|c|}
\hline $\begin{array}{l}\text { Categorical } \\
\text { variables }\end{array}$ & $\begin{array}{l}\text { Percent } \\
\text { distribution }\end{array}$ & $\begin{array}{l}\text { Mean }^{\mathrm{a}} \\
\text { fasting insulin } \\
(\mathrm{mU} / \mathrm{l})\end{array}$ & $\begin{array}{l}\text { Standard } \\
\text { error }^{\mathrm{b}} \\
(\mathrm{mU} / \mathrm{l})\end{array}$ \\
\hline $\begin{array}{l}\text { Males } \\
\text { Females }\end{array}$ & $\begin{array}{l}46.8 \\
53.2\end{array}$ & $\begin{array}{r}8.7 \\
10.6\end{array}$ & $\begin{array}{l}0.20 \\
0.21\end{array}$ \\
\hline $\begin{array}{l}\text { Hispanics } \\
\text { Non-Hispanic } \\
\quad \text { whites }\end{array}$ & 39.5 & 10.3 & 0.21 \\
\hline $\begin{array}{l}\text { Vigorous activity } \\
\text { none } \\
<20 \mathrm{~min}, \\
3 \text { times/week } \\
>20 \mathrm{~min} \text {, at least } \\
3 \text { times/week }\end{array}$ & $\begin{array}{l}33.2 \\
38.8\end{array}$ & 10.3 & 0.17 \\
\hline $\begin{array}{l}\text { Alcohol intake in pa } \\
\text { none } \\
<1 \text { drink/week } \\
1 \text { drink/week to } \\
<1 \text { drink/day } \\
\geq 1 \text { drink/day }\end{array}$ & $\begin{array}{l}\text { ast year } \\
38.8 \\
25.8\end{array}$ & $\begin{array}{r}9.5 \\
10.1\end{array}$ & $\begin{array}{l}0.18 \\
0.22\end{array}$ \\
\hline $\begin{array}{l}\text { Smoking } \\
\text { never smokers } \\
\text { ex-smokers } \\
\text { current smokers }\end{array}$ & $\begin{array}{l}46.5 \\
28.2 \\
25.4\end{array}$ & $\begin{array}{l}9.8 \\
9.4 \\
9.9\end{array}$ & $\begin{array}{l}0.17 \\
0.24 \\
0.19\end{array}$ \\
\hline $\begin{array}{l}\text { Continuous } \\
\text { variables }\end{array}$ & $\begin{array}{l}\text { Mean of } \\
\text { descriptor } \\
\pm \mathrm{SD}^{\mathrm{c}}\end{array}$ & $\begin{array}{l}\text { Mean }{ }^{\mathrm{a}, \mathrm{d}} \\
\% \text { difference } \\
\text { in fasting } \\
\text { insulin }\end{array}$ & $\begin{array}{l}\text { Standarderror } \\
\text { (\% difference } \\
\text { in fasting } \\
\text { insulin) }\end{array}$ \\
\hline Age (years) & $51.8 \pm 12.1$ & $\begin{array}{l}-4.2 \text { per } \\
10 \text { years }\end{array}$ & 0.9 \\
\hline $\begin{array}{l}\text { Body mass index } \\
\left(\mathrm{kg} / \mathrm{m}^{2}\right)\end{array}$ & $25.5 \pm 4.2$ & $\begin{array}{l}12.6 \mathrm{per} \\
5 \mathrm{~kg} / \mathrm{m}^{2}\end{array}$ & 3.0 \\
\hline $\begin{array}{l}\text { Waist circum- } \\
\text { ference }(\mathrm{cm})\end{array}$ & $83.8 \pm 11.4$ & $\begin{array}{l}20.2 \text { per } \\
10 \mathrm{~cm}\end{array}$ & 2.9 \\
\hline
\end{tabular}

${ }^{\mathrm{a}}$ Geometric mean adjusted for gender, ethnicity, vigorous activity, age, body mass index and waist circumference; ${ }^{\mathrm{b}} \mathrm{Ap}$ proximate standard error of the geometric mean; ${ }^{\mathrm{c}} \mathrm{SD}$, standard deviation; ${ }^{\mathrm{d}}$ Mean $\%$ difference in fasting insulin for the specified difference in the continuous descriptor variable

D ata collection and laboratory procedures. Procedures followed were approved and in accordance with University of Colorado Health Sciences Center human subjects guidelines. All subjects attended clinic after a minimum 8-h overnight fast and signed informed consent. Fasting blood samples were drawn and then the subject was given $75 \mathrm{~g}$ of glucose (Koladex; Orangedex, Custom Laboratories, Baltimore, Md., USA). One and 2-h blood samples were drawn and interviews and a physical examination were conducted. Glucose was measured using the glucose oxidase method [17] on venous plasma. Total immunoreactive insulin was measured using the double antibody radioimmunoassay [18]. Fasting insulin concentration was used as the response variable in these analyses because it has been shown to be a strong predictor of subsequent development of NIDDM independent of body mass index (BMI) $[3,4]$ and in subjects with normal glucose tolerance it has been shown to be correlated with whole body glucose uptake $(r=-0.68)$ [19] and insulin sensitivity based on Bergman's minimal model ( $r=-0.53)$ [20].

For the diet assessments, subjects were administered a 24-h diet recall by bilingual interviewers trained and certified by the 
Nutrition Coordinating Center at the University of Minnesota [21]. A two-dimensional food-portion visual [22, 23] and three-dimensional aids (eg. ruler, cups, bowls, glasses, plates, measuring spoons) were used to estimate portion sizes. The nutrient analysis was based on version 14 of the Nutrition Coordinating Center's nutrient data base released in 1987. Total carbohydrate excluded dietary fibre.

The 1980 United States Census self-assessment question on Spanish origin was used to determine ethnicity [24]. BMI was calculated as measured weight in kilograms divided by height in meters squared. The number of grams of alcohol per week was determined using food frequency interview questions about usual type and quantity of alcohol consumed in the last year. Frequency and duration of vigorous activity in current work and leisure time was determined from the questionnaire and included any activity considered by the respondent to be strenuous or to cause symptoms such as fatigue, increased heart rate or sweating [25].

\section{Statistical analysis}

Characteristics of the study population at their initial visit (Tables 1 and 2) were summarized using the Statistical Analysis System (SAS) [26]. The SAS procedure PROC REG was used to calculate partial correlations in Table 3 and PROC MIXED [27] was used for the regression analyses summarized in Figures 1 and 2. Data from subjects with one, two or three visits are included in these analyses. PROC MIXED estimates the random subject effects and accommodates the unbalanced design and time-varying covariates. This procedure takes advantage of the additional within-subject information from individuals with more than one visit without losing the between subject information from subjects with a single visit [28]. We have not only enhanced precision with multiple measures on the same subject but the random subject effect has allowed more powerful within-subject comparisons. The subject is acting as its own control with respect to unmeasured factors which both influence insulin concentrations and vary from subject to subject. To the extent that subjects change their diet (day-today or systematically over time), we can evaluate whether changes in diet are associated with changes in insulin concentrations. In these models, the log of fasting insulin concentration from each visit was entered as the dependent variable. Dietary variables, age, BMI, waist circumference, physical activity, smoking and alcohol intake were included as time-varying covariates and sex and ethnicity were entered as non-timevarying covariates. Time was not included in the model. Plots of the standardized residuals were examined for outliers. Outlying observations were removed from the model to determine their influence. The outliers identified did not alter the conclusions and have been included in the analyses presented here.

To determine if associations between dietary factors and fasting insulin were similar in ethnic, gender, physical activity subgroups and at high and low values of the continuous variable BMI, an interaction term between the dietary factor and the potential modifying variable was added to the above model. These models were run for all nutrients listed in Table 2 except protein. Protein was not associated with fasting insulin concentrations $(p=0.93)$ in the base model without interaction terms. After summarizing the results in Figures 1 and 2, selected additional hypothesis-driven models were run to evaluate whether intercorrelation between nutrients explained initial observations. The rationale for these models is provided with the results.

Findings are presented as the percent change in fasting insulin concentrations calculated [29] from the difference in the
Table 2. Mean reported 24-h dietary intake at baseline $(n=$ 1069): San Luis Valley, Colorado, 1984-1988

\begin{tabular}{|c|c|c|}
\hline & $\begin{array}{l}\text { Estimated daily intake } \\
(\mathrm{g})\end{array}$ & $\%$ of Energy \\
\hline Kilojoules & $8,023.7 \pm 3983$ & 100 \\
\hline Fat & $83.0 \pm 49.5$ & $38.0 \pm 8.9$ \\
\hline Saturated fat & $30.6 \pm 19.6$ & $14.0 \pm 4.2$ \\
\hline Monounsaturated fat & $32.4 \pm 20.1$ & $14.8 \pm 4.1$ \\
\hline Oleic acid & $28.9 \pm 18.3$ & $13.2 \pm 3.9$ \\
\hline Polyunsaturated fat & $14.3 \pm 10.8$ & $6.6 \pm 3.3$ \\
\hline Linoleic acid & $12.6 \pm 10.0$ & $5.8 \pm 3.1$ \\
\hline Linolenic acid & $1.4 \pm 0.9$ & $0.6 \pm 0.3$ \\
\hline $\mathrm{EPA}+\mathrm{DHA}^{\mathrm{a}}$ & $0.07 \pm 0.3$ & - \\
\hline Carbohydrate & $203.2 \pm 105.2$ & $46.7 \pm 10.9$ \\
\hline Starch & $98.9 \pm 55.8$ & $21.0 \pm 7.4$ \\
\hline Sucrose & $44.3 \pm 38.3$ & $9.1 \pm 5.9$ \\
\hline Fructose & $17.0 \pm 16.3$ & $3.7 \pm 3.4$ \\
\hline Glucose & $17.4 \pm 15.3$ & $3.8 \pm 3.1$ \\
\hline Protein & $72.6 \pm 38.7$ & $15.5 \pm 4.7$ \\
\hline Total dietary fiber & $16.6 \pm 11.9$ & $9.0^{\mathrm{b}} \pm 5.6$ \\
\hline
\end{tabular}

Table 3. Energy-adjusted ${ }^{\mathrm{a}}$ nutrient correlations at baseline $(n=1070)$ : San Luis Valley, Colorado, 1984-1992

\begin{tabular}{lcr}
\hline & Saturated fat & \multicolumn{1}{l}{ Starch } \\
\hline Kilojoules & $(0.88)$ & $(0.77)$ \\
Fat & $0.68(0.94)$ & $-0.35(0.62)$ \\
$\quad$ Saturated fat & - & $-0.40(0.56)$ \\
$\quad$ Monounsaturated fat & $0.52(0.90)$ & $-0.25(0.62)$ \\
$\quad$ Oleic acid & $0.44(0.88)$ & $-0.23(0.61)$ \\
$\quad$ Polyunsaturated fat & $-0.19(0.54)$ & $-0.05(0.50)$ \\
$\quad$ Linoleic acid & $-0.21(0.52)$ & $-0.04(0.49)$ \\
$\quad$ Linolenic & $0.11(0.66)$ & $-0.12(0.49)$ \\
$\quad$ EPA + DHA & $-0.05(-0.01)$ & $-0.03(-0.01)$ \\
Carbohydrate & $-0.53(0.66)$ & $0.43(0.80)$ \\
$\quad$ Starch & $-0.40(0.56)$ & - \\
$\quad$ Sucrose & $-0.24(0.44)$ & $-0.15(0.39)$ \\
$\quad$ Fructose & $-0.24(0.30)$ & $-0.57^{\mathrm{c}}$ \\
$\quad$ Glucose & $-0.21(0.36)$ & $-0.24(0.21)$ \\
Protein & $0.25(0.80)$ & $-0.24(0.25)$ \\
Total dietary fiber & $-0.30(0.35)$ & $-0.27(0.54)$ \\
\hline
\end{tabular}

${ }^{a}$ Adjusted for energy intake, unadjusted in parentheses; ${ }^{\mathrm{b}}$ EPA + DHA, $\omega-3$ 20:5 and 22:6 fatty acids; ${ }^{\mathrm{c}}$ adjusted for energy and total carbohydrate

predicted log (fasting insulin) for a specified change in the dietary factor (e.g. a $20-\mathrm{g}$ increase in total fat intake). The magnitude, but not statistical significance, of the reported percent change in fasting insulin concentrations in Figures 1 and 2 depends on the specified change chosen for the dietary factor. For total fat, the approximate size change required to bring the mean percent of energy for the study population to the United States recommended dietary intake was used (e.g. a decrease of $20 \mathrm{~g}$ of fat per day at the mean energy intake would bring the percent of energy from fat to approximately $30 \%$ in the study population). For carbohydrate, $45 \mathrm{~g}$ was chosen as an equicaloric change with respect to $20 \mathrm{~g}$ of total fat. Within subtypes of fat and within subtypes of carbohydrates, the same specified change was used (5 g and $10 \mathrm{~g}$, respectively, 


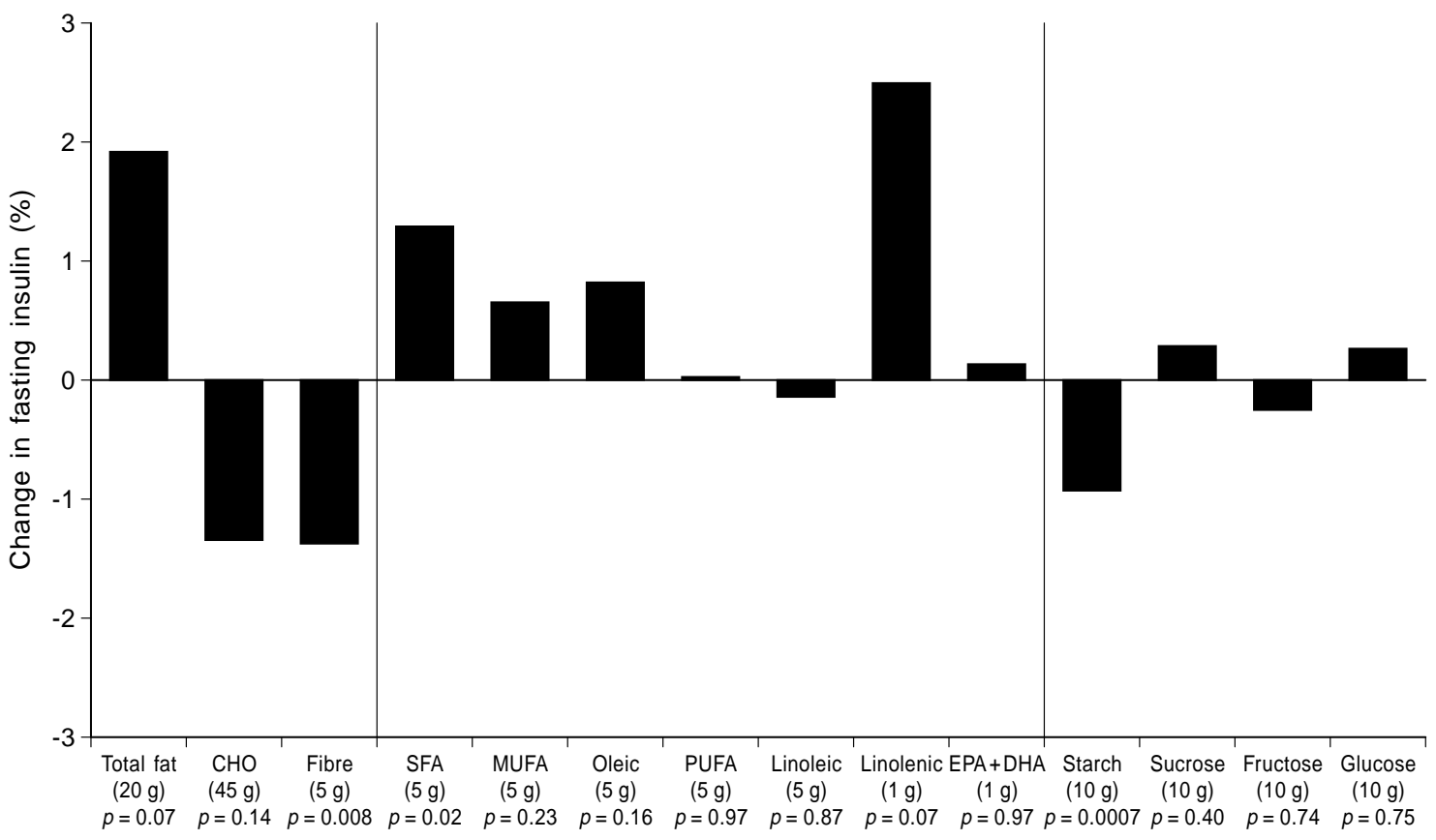

Fig. 1. Adjusted percent change in fasting insulin concentrations for a given difference in nutrient intake (shown in parentheses under each column). Calculated from the regression model including sex, ethnicity, physical activity, age, body mass index, waist circumference, total energy intake and the nutrient

except for the omega- 3 fatty acids which account for a much smaller proportion of total intake) so that the percent change in insulin concentrations could be compared on an energy equivalent basis.

\section{Results}

The subjects included in the analyses described here were $53.2 \%$ female, and $39.5 \%$ self-identified as Hispanic (Table 1). The average age was 51.8 years and average BMI was $25.5 \mathrm{~kg} / \mathrm{m}^{2}$. Drinking any alcohol in the last year was reported by $61 \%$ of subjects, but only $15.6 \%$ reported one drink or more per day. At baseline, $25.4 \%$ of persons were current smokers. Female gender $(p<0.0001)$, Hispanic ethnicity $(p<$ $0.0001)$, no reported vigorous activity $(p=0.002)$, lower age $(p<0.0001)$, higher BMI $(p<0.0001)$ and higher waist circumference $(p<0.0001)$ were associated with hyperinsulinaemia (Table 1 ). No systematic trend in insulin concentrations according to alcohol intake or smoking status was observed.

The average intake of fat, carbohydrate and protein (as percent of energy) was 37, 48 and $15 \%$, respectively, at the baseline visit. Further detail on dietary intakes in these subjects is presented in Table 2 and in previous publications $[30,31]$. Subjects were asked if the intake reported in the past $24 \mathrm{~h}$ was usual for them. "Usual" intakes were reported for $81.7 \%$ of subject visits, "considerably less than usual" for $13.2 \%$ and "considerably more than usual" for $5.0 \%$. The distribution of energy by fat, carbohydrate and protein, as well as by subtypes of fat and carbohydrate are consistent with estimates from food consumption surveys for the United States population conducted by the Department of Agriculture [8]. The correlation between nutrients in the diet can make it difficult to determine which nutrient is directly related to insulin concentrations. The degree of correlation may also vary across populations and contribute to different findings across studies. Table 3 shows both crude and energy-adjusted partial correlations for all nutrients compared with saturated fat and starch intake, the nutrients which showed the strongest associations with fasting insulin concentrations in subsequent analyses. While crude correlations between nutrients tended to be high, energy-adjusted correlations were much lower.

Figure 1 shows the percent change in fasting insulin levels associated with a given gram change in intake of each nutrient. High saturated fat intake and low starch and fibre intake, in separate models, were significantly associated with higher fasting insulin concentrations after adjusting for age, gender, ethnicity, vigorous activity, BMI, waist circumference and total energy (Fig.1). High total fat and linolenic acid intakes were marginally associated with higher fasting insulin concentrations. The associations in Figure 1 were similar in men and women and at all levels of vigorous activity (data not shown). The statistically significant associations in Figure 1 were seen in both Hispanics and non-Hispanic whites. Polyunsaturated fat, linoleic acid, fructose and 


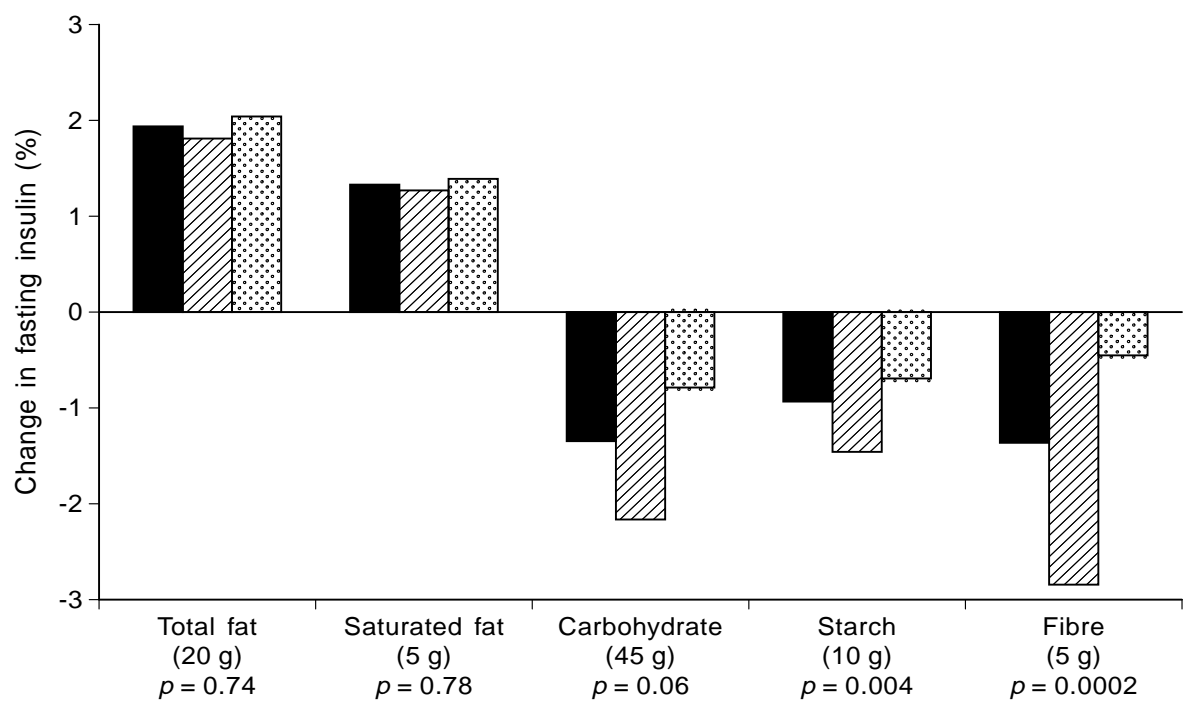

Fig. 2. Adjusted percent change in fasting insulin concentrations for a given difference in nutrient intake by level of body mass index (BMI): all BMIs combined, $\mathbb{Z}$ BMI of 22, 표 BMI of 28. Calculated from the regression model including sex, ethnicity, physical activity, age, BMI, waist circumference, total energy intake, the nutrient and an interaction term, $\mathrm{BMI} \times$ nutrient, where $\mathrm{BMI}$ was modelled as a continuous variable. The $p$-value for the interaction term is presented testing whether the diet effect differs by level of BMI

glucose showed no association with fasting insulin concentrations in the combined group, but the associations were significantly different in Hispanics compared to non-Hispanic whites (interaction $p$-values of $0.03,0.03,0.04$ and 0.03 , respectively). All four nutrients were inversely associated with fasting insulin concentrations in Hispanics, while in non-Hispanic whites the associations were near zero. These ethnic differences remained when the fatty acid models were further adjusted for saturated fat intake and when the sucrose and fructose models were adjusted for starch intake.

The presence of obesity might alter the effect of dietary factors on insulin concentrations because of obesity's strong effect on insulin concentrations. The associations of total and saturated fat with fasting insulin concentrations did not vary by level of obesity (Fig. 2). However, the associations of total carbohydrate, starch and fibre with fasting insulin concentrations were strongest in the leaner subjects.

Additional analyses were conducted to investigate specific hypotheses about relationships between nutrients. There was no apparent interaction between saturated fat and fibre (or starch) intake, suggesting that the positive association between saturated fat and fasting insulin concentrations was present at all levels of fibre intake (data not shown). Since monounsaturated fat has been suggested as an alternative to saturated fat or carbohydrate in cholesterol-lowering diets, we were concerned from the results in Figure 1 that monounsaturated fat might have deleterious effects on insulin sensitivity. On the other hand, to the extent that people reporting high saturated fat intakes also eat more monounsaturated fats, the apparent adverse association of monounsaturated fat with insulin concentrations may be due only to its association with saturated fat intake (Table 3). When saturated fat was held constant by adding it as a term in the regression model with oleic acid (the primary monounsaturated fatty acid in the diet and more strongly related to insulin concentrations in Figure 1 than total monounsaturated fat), the oleic acid effect was reduced by $73 \%$ to near zero $(p=0.74)$. The effect of linolenic acid was only reduced by $18 \%(p=0.15)$ after further adjustment for saturated fat intake. Animal studies have suggested that linolenic acid in the absence of linoleic acid may improve insulin sensitivity [32]. However, a scatter plot of linoleic acid intake by linolenic acid intake revealed that there were no subjects with high linolenic acid intakes in the absence of linoleic acid intakes to allow us to test this hypothesis.

It was also of interest to explore the apparent lack of effect of sucrose on insulin concentrations, since sucrose has been implicated in the development of insulin resistance [34]. When both carbohydrate and energy were held constant in the model, high sucrose intake was significantly associated with higher insulin concentrations. This suggests that eating sucrose instead of other sources of carbohydrate may be detrimental to insulin sensitivity. To further determine if this was due to beneficial effects of starch or adverse effects of sucrose, terms for starch, sucrose, fructose and glucose were simultaneously included in the model predicting fasting insulin concentrations. In this model, starch remained significantly and inversely related to fasting insulin concentrations, and sucrose, glucose and fructose were not associated with fasting insulin. 


\section{Discussion}

We tested the hypothesis that diets high in total and saturated fat and low in fibre were associated with hyperinsulinaemia by collecting 24 -h diet recalls and determining fasting serum insulin concentrations in a geographically based sample of non-diabetic subjects. Subjects were seen on up to three visits from 1984 to 1992. Longitudinal data analysis allowed us to improve analytic power by incorporating information on both the cross-sectional diet-insulin associations between subjects and the longitudinal diet-insulin associations within subjects. In these data, diets high in total and saturated fat and low in starch and fibre were significantly associated with fasting hyperinsulinaemia. No associations with fasting insulin concentrations were observed for monounsaturated fat, polyunsaturated fats, sucrose, glucose and fructose. Fasting hyperinsulinaemia, a marker for insulin resistance, precedes the onset of glucose intolerance in NIDDM [2]. The findings reported here are consistent with our earlier findings that high fat/low carbohydrate diets predict the development of glucose intolerance. They further suggest that such diets may operate through insulin resistance mechanisms. Therefore, diet may be an important modifiable risk factor early in the natural history of pre-clinical glucose intolerance.

This study suggests that diets enriched in complex carbohydrates are associated with lower fasting insulin concentrations. While some early clinical studies suggested that high carbohydrate diets increased basal insulin concentrations [33], others observed inverse associations [34]. Crapo et al. [35] found that carbohydrate as a) mixed meals compared to liquid diets and b) starch compared to sucrose, resulted in a lower glucose and insulin response. These studies highlighted the importance of the form of carbohydrate and other meal components in determining the metabolic response. For many years the dietary recommendations of the American Diabetes Association (ADA) advocated restriction of sucrose intake. A number of studies in animals [36] and humans [37, 38] have supported the idea that sucrose consumption is associated with adverse effects on insulin sensitivity and glucose intolerance. However, the most recent ADA nutritional guidelines removed this restriction on sucrose consumption in response to a growing number of clinical trials which failed to demonstrate adverse effects on glucose control in those with diabetes $[8,6]$. No adverse effects of sucrose were seen in the current study of subjects with normal glucose tolerance when energy intake alone was kept constant. However, further analyses holding both energy intake and carbohydrate constant revealed a significant positive association between sucrose intake and fasting insulin concentrations, suggesting that substituting sucrose for other carbohydrates may have deleterious effects on fasting insulin concentrations.

A large number of clinical investigations after the mid-1970s reported the effects of dietary fibre on metabolic responses in normal and diabetic subjects [39, 40-47]. Among randomized crossover studies of high and low fibre intake in natural food form and administered under isocaloric conditions, the most consistent finding has been an inverse association between fibre intake and postprandial insulin concentrations. In support of this finding, gastric inhibitory polypeptide (GIP) the primary humoral secretion of the intestine responsible for both the transitory and prolonged phases of insulin release [48] has been measured in higher concentrations in the blood following low fibre meals [49]. The primary site of GIP secretion is the proximal small intestine. Since dietary fibre slows gastric emptying and separates nutrients from digestive enzymes and absorptive surfaces, nutrients associated with a high-fibre meal are absorbed distally relative to nutrients associated with a low-fibre meal. This results in reduced GIP secretion. The statistically significant inverse association of dietary fibre and starch with fasting insulin concentrations reported here in a free-living population is consistent with the hypothesis of a beneficial effect of diets enriched with complex carbohydrates and fibre on insulin sensitivity.

Persons with a higher BMI (later in the progression from normal insulin action to severe insulin resistance and ultimately diabetes in some) were observed to have less beneficial effects from the addition of complex carbohydrates and fibre to the diet than leaner subjects. However, obese persons still experience the deleterious effects of total fat and saturated fat on fasting insulin concentrations when compared to lean individuals. This may occur as the net rate of lipolysis increases with increasing fat mass, increasing plasma non esterified fatty acid (NEFA) concentrations; an effect which overrides the beneficial effects of dietary carbohydrates and fibre.

High-fat diets have been shown to cause insulin resistance in rats [50]. Animal models have shown highfat diets and increased levels of NEFAs to cause insulin resistance in hepatocytes [51], adipose cells [52], and skeletal muscle [53] in vitro, and to be involved in the pathogenesis of NIDDM $[54,55]$. In humans, high-fat diets have been related to deterioration of carbohydrate metabolism. For the Pima Indians in Arizona, the transition from an agrarian to a modern society was associated with the consumption of increasing amounts of dietary fat, decreasing amounts of dietary carbohydrate and a deterioration in insulin sensitivity [56, 57]. Diets high in total fat may lead to increased circulating NEFAs [7, 58]. In 1963, Randle et al. [59] suggested that NEFAs, an important oxidative fuel and the primary fuel for resting muscle, heart, liver and the renal cortex, compete with 
glucose as an oxidative fuel in muscle [60]. Increased NEFA uptake and oxidation in muscle results in impaired glucose metabolism via the glucose-NEFA cycle $[58,61,62]$. In addition, high-fat diets have been associated with reduced expression of GLUT4 glucose transporters [63].

While increases in total fat intake were associated with insulin resistance, it appears that specific fatty acids may be more or less potent in inducing this metabolic abnormality. Previous studies have generated interest in "good fats" including polyunsaturated fats, monounsaturated fats including oleic acid, and omega-3 fatty acids. Investigations in rats have demonstrated that the dietary lipid profile is an important determinant of tissue phospholipid composition [64] which may in turn influence insulin sensitivity by altering membrane fluidity and insulin signalling. In humans, decreased concentrations of polyunsaturated fatty acids in skeletal-phospholipids have been associated with decreased insulin sensitivity [65]. Storlien et al. [50] have demonstrated that diets high in saturated, monounsaturated or polyunsaturated fatty acids led to severe insulin resistance in rats. Substituting fish oil for these fats reversed the effects. These animal data are at odds with data obtained in normal individuals [66] and those with NIDDM [67] where diets enriched in monounsaturated fats have not been found to worsen glycaemia and have been advocated as an alternative to the usual low-fat diabetic diet [68]. It may be that the partitioning of different fatty acids between storage (as triglyceride in liver, muscle and adipose tissue) and oxidation may explain some of the variability seen between different fats. In the current study, saturated fat, monounsaturated fat and linolenic acids appeared associated with hyperinsulinaemia, while polyunsaturated fatty acids and linoleic acid were not. Leyton et al. [69] examined the metabolism of a number of fatty acids in rats and found that among unsaturated fats, alpha linolenic and oleic acid were the most highly oxidized, while linoleic and the highly polyunsaturated fatty acids such as arachidonic were less likely to be oxidized. Those fatty acids that are more efficiently oxidized may compete more effectively against glucose for oxidation with resulting decrease in peripheral glucose disposal. Further analyses in the current study suggested that the apparent adverse effect of monounsaturated fat on fasting insulin concentrations may be an indirect effect resulting from the association of monounsaturated fat with saturated fat in the diets of this population.

Although experimental studies allow controlled alteration of diets and tight control of potentially confounding variables, inferences from these studies have been limited by: 1) the short period of time on special diets, which 2) often contain extreme contrasting amounts of nutrients (e.g. carbohydrate or fibre); 3 ) sometimes by lack of control for potential modifying variables such as obesity; and 4) by limited statistical power. Observations in free-living populations, although not as tightly controlled as in experimental studies, offer the potential to study the effects of habitual diet on metabolic parameters and to determine if findings in animal and clinical studies translate to effects measurable at the population level. Epidemiologic studies have reported that intakes high in total fat $[9,11,10]$, saturated fat $[9,11,10]$ and monounsaturated fat $[9,11]$ and intakes low in carbohydrate $[9,11]$ and fibre [9] correlate with higher fasting insulin concentrations. These studies have been conducted in adult, predominantly Caucasian, populations including men with coronary artery disease [9], non-diabetic women twins [11] and men followed in the Normative Aging Study [10]. Four-day food records [9] and food frequency questionnaires [11, 10] were used to describe diet-insulin associations across subjects at one point in time in these studies. The CARDIA study of young black and white men and women [aged 18-30 years] observed a positive association between sucrose (28-day diet history) and fasting insulin concentrations, but did not observe significant associations for total fat, saturated fat, starch or carbohydrate [27]. Given the young age and consistent inverse associations between fasting insulin concentrations and physical activity in the CARDIA population, further analysis of grams of total and saturated fat adjusted for energy intake (rather than use of nutrient densities) and evaluation of activity as a modifier of associations between dietary fat and insulin would be of interest. Lovejoy and DiGirolamo [12] assessed insulin sensitivity (the inverse of insulin resistance), with the frequently sampled intravenous glucose tolerance test and Bergman's minimal model and compared this to dietary intakes reported for the past year using a food frequency questionnaire [12]. In this small sample of lean and obese men and women, insulin sensitivity was inversely associated with total fat intake and positively associated with fibre intake, consistent with findings reported here.

Our findings are based on repeated assessments of 24-h dietary recall and fasting insulin concentrations collected on up to three occasions in Hispanic and non-Hispanic white men and women of the SLVDS. The magnitude of these dietary effects deserves comment. A change in fasting insulin concentrations of 2 $3 \%$ as observed here with a 20 -g difference in fat is comparable to the change in insulin associated with a 1-unit change in BMI in this data set. The 24-h diet recall method has reduced power and the size of estimated effects are likely to be attenuated due to dayto-day variability. Nonetheless, the method is generally considered to give a good estimate of the group mean. This is especially true in diverse populations, where variations in food choices, preparation methods or portion sizes may not be captured by a closedended assessment such as a food frequency questionnaire. The consistency of findings with respect to 
high total and saturated fat and low carbohydrate and fibre across the populations described above, as well as across study designs and assessment methods provides strong evidence that these associations are real and not an artifact of a particular method or population sample. Our findings are consistent with previous reports from the SLVDS relating high fat/low carbohydrate diets to glucose intolerance $[13,14]$. The findings support current dietary guidelines for the United States, the American Diabetes Association, the American Heart Association and the American Cancer Society recommending reduced intakes of total and saturated fat and increased intakes of fruits and vegetables.

A cknowledgements. The authors gratefully acknowledge the staff and participants of the San Luis Valley Diabetes Study who made this study possible; the Nutrition Coordinating Center at the University of Minnesota for interviewer training, data coding, and nutrient analysis of the 24-h diet recalls; and the laboratory of the University of Colorado Health Sciences Center General Clinical Research Center for conducting blood chemistry analyses. This work was supported by NIH grants DK-30747 and CRC-RR00051.

\section{References}

1. Stout RW (1990) Insulin and atheroma. Diabetes Care 13: 631-654

2. Reaven GM (1993) Role of insulin resistance in the pathophysiology of non-insulin dependent diabetes mellitus. Diab Metab Rev 9: 5S-12S

3. Haffner SM, Stern MP, Mitchell BD, Hazuda HP, Patterson JK (1990) Incidence of type II diabetes in Mexican Americans predicted by fasting insulin and glucose levels, obesity and body-fat distribution. Diabetes 39: 283-288

4. Baxter J, Hamman RF, Hoag S, Marshall JA, Rewers M (1993) Hyperinsulinemia does not explain the ethnic difference in incidence of glucose intolerance between Hispanics and non-Hispanic whites. The San Luis Valley Diabetes Study. Diabetes 42 [Suppl 1]: 30A (Abstract)

5. Nutrition recommendations and principles for people with diabetes mellitus (1996) Diabetes Care 19S1:S16-S19

6. Wolever TMS, Miller JB (1995) Sugars and blood glucose control. Am J Clin Nutr 62[Suppl]:212S-217S

7. Smith U (1994) Carbohydrates, fat, and insulin action. Am J Clin Nutr 59 [Suppl]: 686S-689S

8. Franz MJ, Horton ES, Bantle JP et al. (1994) Technical Review: nutrition principles for the mangement of diabetes and related complications. Diabetes Care 17: 490-518

9. Maron DJ, Fair JM, Haskell WL (1991) Saturated fat intake and insulin resistance in men with coronary artery disease. Circulation 84: 2020-2027

10. Parker DR, Weiss ST, Troisi R, Cassano PA, Vokonas PS, Landsberg L (1993) Relationship of dietary saturated fatty acids and body habitus to serum insulin concentrations: the Normative Aging Study. Am J Clin Nutr 58: 128-136

11. Mayer EJ, Newman B, Quesenberry CP, Selby JV (1993) Usual dietary fat intake and insulin concentrations in healthy women twins. Diabetes Care 16: 1459-1469

12. Lovejoy J, DiGirolamo M (1992) Habitual dietary intake and insulin sensitivity in lean and obese adults. Am J Clin Nutr 55: 1174-1179
13. Marshall JA, Hamman RF, Baxter J (1991) High fat, low carbohydrate diet, and the onset of non-insulin-dependent diabetes mellitus: The San Luis Valley Diabetes Study. Am J Epidemiol 134: 590-603

14. Marshall JA, Hoag S, Shetterly S, Hamman RF (1994) Dietary fat predicts conversion from impaired glucose tolerance to NIDDM: The San Luis Valley Diabetes Study. Diabetes Care 17 (1): 50-56

15. Report of a WHO Study Group (1985) Diabetes mellitus. World Health Organization Technical Report Series 727. World Health Organization, Geneva, Switzerland

16. Hamman RF, Marshall JA, Baxter J et al. (1989) The San Luis Valley Diabetes Study: methods and prevalence of non-insulin-dependent diabetes mellitus (NIDDM) in a biethnic population. Am J Epidemiol 129 (2): 295-311

17. Beckman Instruments (1988) Glucose Analyzer 2 Operating Manual. Beckman Instruments, Fullerton, California

18. Desbuquois B, Arbaugh GD (1971) Use of polyethylene glycol to separate free and antibody-bound peptide hormones in radioimmunoassays. J Clin Endocrinol Metab 33: 732-738

19. Laakso M (1993) How good a marker is insulin level for insulin resistance? Am J Epidemiol 137: 959-965

20. Anderson RL, Hamman RF, Savage PJ et al. for the Insulin Resistance Atherosclerosis Study (1995) Exploration of simple insulin sensitivity measures derived from frequently sampled intravenous glucose tolerance (FSIGT) tests. Am J Epidemiol 142: 724-732

21. Dennis B, Ernst N, Hjortland M, Tillotson J, Grambsch V (1980) The NHLBI nutrition data system. J Am Diet Assoc 77: 641-647

22. Posner BM, Morgan JL (1982) Dietary interviewing instructional manual: the use of the $2 \mathrm{D}$ food portion visual. Nutrition Consulting Enterprises, Newton, Massachusetts

23. Posner BM, Borman CL, Morgan JL, Borden WS, Ohis JC (1982) The validity of a telephone-administered 24-hour dietary recall methodology. Am J Clin Nutr 36: 546-553

24. US Bureau of the Census (1983) 1980 Census of Population, vol 1. General population characteristics. US GPO (PC80-1-C7), Appendix B, Washington, D. C.

25. Mayer EJ, Alderman BW, Regensteiner JG et al. (1991) Physical activity assessment measures compared in a biethnic rural population: The San Luis Valley Diabetes Study. Am J Clin Nutr 53(4): 812-820

26. SAS Institute Inc. (1985) SAS STAT Guide for Personal Computers, version 6. Cary, NC: SAS Institute Inc.

27. SAS Institute Inc. (1992) SAS Technical Report P-229, SAS/STAT Software: Changes and Enhancements, Release 6.07, SAS Institute Inc., Cary, NC

28. Ware JH (1993) Analysis of longitudinal data: choosing and interpreting regression models. Eur Respir J 6: 325-327

29. Maniolo TA, Savage PJ, Burke GL et al. (1991) Correlates of fasting insulin levels in young adults: The CARDIA Study. J Clin Epidemiol 44: 571-578

30. Marshall JA, Lopez TK, Shetterly SM, Baxter J, Hamman RF (1995) Association of education level with atherogenic diets in a rural biethnic population. Am J Prev Med 11 (5): 294-300

31. Lopez TK, Marshall JA, Shetterly SM, Baxter J, Hamman RF (1995) Ethnic differences in micronutrient intake in a rural biethnic population. Am J Prev Med 11 (5): 301305

32. Storlien LH, Jenkins AB, Chisholm DJ, Pascoe WS, Khouri S, Kraegen EW (1991) Influence of dietary fat composition on development of insulin resistance in rats: relationship to muscle triglyceride and $\omega-3$ fatty acids in muscle phospholipid. Diabetes 40: 280-289 
33. Grey N, Kipnis DM (1971) Effect of diet composition on the hyperinsulinemia of obesity. New Engl Med 285: 827831

34. Brunzell JD, Lerner RL, Hazzard WR, Porte D, Bierman EL (1971) Improved glucose tolerance with high carbohydrate feeding in mild diabetes. New Engl J Med 284: 521524

35. Crapo PA, Reaven G, Olefsky J (1976) Plasma glucose and insulin responses to orally administered simple and complex carbohydrates. Diabetes 25: 741-747

36. Pagliassotti MJ, Shahrokhi KA, Moscarello M (1994) Involvement of liver and skeletal muscle in sucrose-induced insulin resistance: dose-response studies. Am J Physiol 266: R1637-R1644

37. Hollenbeck CB, Coulston AM, Reaven GM (1986) Glycemic effects of carbohydrates: a different perspective. Diabetes Care 9: 641-647

38. Coulston AM, Hollenbeck CB, Swislocki ALM, Chen YDI, Reaven GM (1987) Deleterious metabolic effects of high carbohydrate, sucrose containing diets in patients with NIDDM. Am J Med 82: 213-219

39. Haber GB, Heaton KW, Murphy D, Burroughs LF (1977) Depletion and disruption of dietary fibre: effects on satiety, plasma glucose, and serum insulin. Lancet 2: 679-682

40. O'Dea K, Nestel PJ, Antonoff L (1980) Physical factors influencing postprandial glucose and insulin responses to starch. Am J Clin Nutr 33: 760-765

41. Burke BJ, Hartog M, Heaton KW, Hooper S (1982) Assessment of the metabolic effects of dietary carbohydrate and fibre by measuring urinary excretion of C-peptide. Hum Nutr Clin Nutr 36C: $373-380$

42. Potter JG, Coffman KP, Reid RL, Krall JM, Albrink MJ (1981) Effect of test meals of varying dietary fibre content on plasma insulin and glucose response. Am J Clin Nutr 34: $328-334$

43. Albrink MJ, Newman T, Davidson PC (1979) Effects of high and low fiber diets on plasma lipids and insulin. Am J Clin Nutr 32: 1486-1491

44. Ullrich IH, Albrink MJ (1982) Lack of effect of dietary fiber on serum lipids, glucose, and insulin in healthy young men fed high starch diets. Am J Clin Nutr 36: 1-9

45. Kay RM, Grobin W, Track NS (1981) Diets rich in natural fibre improve carbohydrate tolerance in maturity-onset, non-insulin dependent diabetics. Diabetologia 20: 18-21

46. Karlstrom B, Vessby B, Asp NG et al. (1984) Effects of an increased content of cereal fibre in the diet of type 2 (noninsulin-dependent) diabetic patients. Diabetologia 26: 272-277

47. Hollenbeck CB, Coulston AM, Reaven GM (1986) To what extent does increased dietary fiber improve glucose and lipid metabolism in patients with non-insulin-dependent diabetes mellitus (NIDDM)? Am J Clin Nutr 43: 16-24

48. Brown JC, Dryburgh JR, Ross SA, Dupre J (1975) Identification and actions of GIP. Recent Prog in Hormone Res 31: 487-532

49. Morgan LM, Goulder TJ, Tsiolakis D, Marks, V, Alberti KGMM (1979) The effect of unabsorbable carbohydrate on gut hormones: modification of post-prandial GIP secretion by guar. Diabetologia 17: 85-89

50. Storlein LH, James DE, Burleigh KM, Chisholm DJ, Kraegen EW (1986) Fat feeding causes widespread in vivo insulin resistance, decrease energy expenditure, and obesity in rats. Am J Physiol 251: E576-E583

51. Svedberg J, Bjorntorp P, Smith U, Lonnroth P (1992) Effect of free fatty acids on insulin receptor binding and tyrosine kinase activity in hepatocytes isolated from lean and obese rats. Diabetes 41: 294-298

52. Hunnicutt JW, Hardy RW, Williford J, McDonald JM (1994) Saturated fatty acid-induced insulin resistance in rat adipocytes. Diabetes 43: 40-45

53. Pagliassotti MJ, Shahrokhi KA, Hill JO (1993) Skeletal muscle glucose metabolism in obesity-prone and obesityresistant rats. Am J Physiol 264:R1224-R1228

54. Kraegen EW, Clark PW, Jenkins AB, Daley EA, Chisholm DJ, Storlien LH (1991) Development of muscle insulin resistance after liver insulin resistance in high-fat-fed rats. Diabetes 40: 1397-1403

55. Unger RH (1995) Lipotoxicity in the pathogenesis of obesity-dependent NIDDM: genetic and clinical implications. Diabetes 44: 863-870

56. Boyce VL, Swinburn BA (1993) The traditional Pima Indian Diet: composition and adaptation for use in a dietary intervention study. Diabetes Care 16: 369-371

57. Swinburn BA, Boyce VL, Bergman RN, Howard BV, Bogardus C (1991) Deterioration in carbohydrate metabolism and lipoprotein changes induced by modern, high fat diet in Pima Indians and Caucasians. J Clin Endocrinol 73: 156-165

58. Griffiths AJ, Humphreys SM, Clark ML, Fielding BA, Frayn KN (1994) Immediate metabolic availability of dietary fat in combination with carbohydrate. Am J Clin Nutr 59: 53-59

59. Randle P, Garland P, Hales N, Newsholme E (1963) The glucose-fatty acid cycle: its role in insulin sensitivity and the metabolic disturbances of diabetes mellitus. Lancet 1: 785-789

60. Coppack SW, Jensen MD, Miles JM (1994) In vivo regulation of lipolysis in humans. J Lipid Res 35: 177-193

61. Felley CP, Felley EM, va Melle GD, Frascarolo P, Jequier E, Felber JP (1989) Impairment of glucose disposal by infusion of triglycerides in humans: role of glycemia. Am J Physiol 256: E747-752

62. Johnson AB, Argyraki M, Thos JC, Cooper BG, Fulcher G, Taylor R (1992) Effect of increased free fatty acid supply on glucose metabolism and skeletal muscle glycogen synthase activity in normal man. Clin Sci 82: 219-226

63. Pedersen O, Kahn CR, Flier JS, Kahn BB (1991) High fat feeding causes insulin resistance and a marked decrease in the expression of fat cells of rats. Endocrinology 129: 771777

64. Pan DA, Storlien LH (1993) Dietary lipid profile is a determinant of tissue phospholipid fatty acid composition and rate of weight gain in rats. J Nutr 123: 512-519

65. Borkman M, Storlien LH, Pan DA, Jenkin AB, Chisholm DJ, Campbell LV (1993) The relation between insulin sensitivity and the fatty-acid composition of skeletal-muscle phospholipids. New Engl J Med 328: 238-244

66. Uusitupa M, Schwab U, Makimattila S et al. (1994) Effects of two high-fat diets with different fatty acid compositions on glucose and lipid metabolism in healthy young women. Am J Clin Nutr 59: 1310-1316

67. Garg A, Bonanome A, Grundy SM, Zhang Z-J, Unger RH (1988) Comparison of a high-carbohydrate diet with a highmonounsaturated fat diet in patients with NIDDM. New Engl J Med 319: 829-834

68. Campbell LV, Marmot PE, Dyer JA, Borkman M, Storlien LH (1994) The high-monounsaturated fat diet as a practical alternative for NIDDM. Diabetes Care 17: 177-182

69. Leyton J, Drury PJ, Crawford MA (1987) Differential oxidation of saturated and unsaturated fatty acids in vivo in the rat. Brit J Nutr 57: 383-393 